\title{
On the Systematic Functions of Innovation Knowledge in Marxist Innovation Education
}

\author{
Qing LUO \\ The School of Marxism \\ Zhaoqing University, \\ Zhaoqing City, Guangdong 526061, China \\ e-mail:457545867@qq.com
}

\begin{abstract}
This article applied the system-constructing method of the separation and combination in exploring the education functions for innovation knowledge, and demonstrated how to provide the innovation knowledge contents systematically. Only when the innovation knowledge system is prepared, can we obtain the indispensable intellectual or nonintellectual factors for the innovation quality education. The innovation knowledge provides methods, standards and contents. The content system can be constructed by combining with the innovation spirit, the innovation ability, the innovation method, the innovation resources and the innovation management, etc.
\end{abstract}

Keywords-innovation; innovation knowledge; innovation quality; Marxist innovation education

\section{INTRODUCTION}

Innovation education plays a dominant role in the education of innovation and entrepreneurship, seeing from Marxist innovation education, because the education of entrepreneurship is only possible under the condition that innovation knowledge is provided, without innovation knowledge, no entrepreneurship can be achieved by education. The impotence of knowledge is realized by more and more entrepreneurs and educators, with the accelerating of knowledge economy, within which human capital or resource is taken as the leading factor. And within the human capital or resource, innovation quality is taken as the leading factor, which is dominated by the knowledge of innovation attained mainly through education. Innovation quality is decisive to innovation education, and the innovation knowledge is decisive to innovation quality, so as to the innovation education, but how? In the following, manifested is the systematic reason with Marxism materialist dialectics. The effectiveness of the materialist dialectics has been well proved by recent research, such as: Innovation is revealed as a systematic contradiction, composed by the contradictory interaction of scientific and technological innovation, economic innovation, politic innovation, cultural innovation and social innovation [1].

\section{The InNOVATION KNOWLEDGE SYSTEMATIC STRUCTURES}

\section{A. The Innovation Knowledge as Systematic Contradiction}

It is obvious that the research result of innovation system is achieved by the application of the materialist dialectics, otherwise, no inner contradictions can be found for innovation. And the materialist dialectics' efficiency has been well proved in analyzing innovation resources into objective resource of innovation and subjective ones [2]. In the same way, the innovation knowledge can be viewed as a systematic contradiction, which is produced through dialectic interaction of innovation and knowledge. Knowledge is just knowledge before the dialectic interaction, when has dialectic interaction with innovation, the knowledge as normal as it is, obtains its qualitative change, is transformed into the innovation knowledge. The knowledge is then actually proved innovative in the practice of innovation.

\section{B. The Innovation Knowledge in Innovation Quality System}

By Marxism, the function of any system is determined by its structure, while its factors remain the same. Innovation education taken as a system should function to improve innovation quality, whatever means being applied. Here, in order to improve innovation quality, we apply the materialist dialectics to manifest the systematic reasons that make the innovation knowledge function in the education of innovation and entrepreneurship. The systematic reason generally speaking, composes of the two aspects of systematic factors and systematic structure.

In terms of systematic factors, Marxist innovation education has innovation quality as a whole containing: innovation spirit, innovation awareness, innovation willpower, innovation ability, innovation method, innovation resources, objective innovation resources, subjective innovation resources, eventually, innovation knowledge and innovation management, etc. Within which, the innovation knowledge is the eye for this research to verify the main reasons contributing to the education of innovation quality.

In terms of systematic structure, as it shows in the following fig. 1, each upper system factor is composed by the two aspects' interaction of lower system factors, and the former functions the principle aspect, plays decisive role; the latter functions the secondary aspect, plays reactive role, as a wife in a couple, can born new contradictions. That is, the latter bears the potential lower system factors, though it is only reactive power, being the secondary aspect. For example, in the upper system factor of subjective innovation resources as fig. 1, its content factors are produced through the interaction of innovation knowledge and innovation management, which 
belong to the lower system factors, the innovation knowledge functions the principle aspect, plays decisive role, and the innovation management functions the secondary aspect, plays reactive role. This can be well understood, that if any systemconstructing innovation were in lack of knowledge, the innovation management must be impossible to happen in short of "software", and it is the prerequisite knowledge being innovative that makes management innovative, so the innovation knowledge is the decisive subjective resource of innovation, functions principle generally speaking. Meanwhile, though the innovation management functions the secondary aspect, it can also born new contradictions, usually can be concluded as the management of visible factors and the management of invisible factors. From this systematic structure of innovation quality factors, we can observe that the innovation knowledge is an impotent systematic factor, which functions the principle aspect in the subjective innovation resource, and dominates the innovation management.

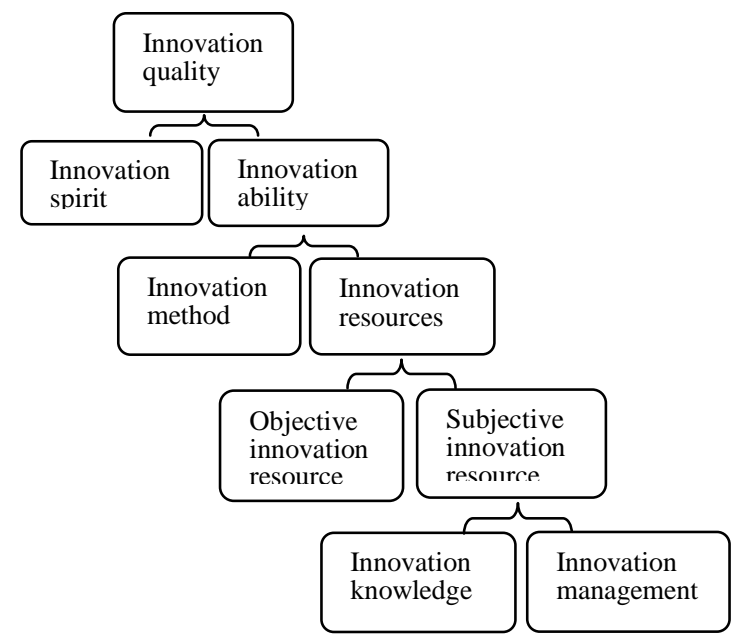

Fig. 1. Contradictions of innovation quality system

\section{The INNOVAtion KNOWLEDGE CENTERED SySTEMATIC STRUCTURE}

The fig. 2 exemplifies all the innovation quality education fields that are centered to the innovation knowledge. What are the reasons for the innovation knowledge centered structure? Is it just because the knowledge reflects other fields? They can be examined also from two aspects, under the direction of the materialist dialectics.

The principle aspect is that there is no innovation comes into being outside the innovation knowledge, since all investigations about successful innovation practice prove they are based on knowledge. All innovations are knowledge-based innovations. The logic lies in, their success makes ordinary knowledge transformed into innovation knowledge, and then the innovation knowledge is found the common factor contributing to all the innovation practices. So the innovation quality education has to have its fields combined with the innovation knowledge individually, to be specific, just as the fig. 2 shows: innovation spirit is combined with it to get knowledge of the innovation spirit; innovation ability is combined with it to get knowledge of the innovation ability; and innovation management is combined with it to get knowledge of the innovation management. It is the same, when it comes to the field of innovation method and the field of innovation resources. The innovation knowledge involves all intellectual factors needed for the innovation quality education to embrace success, and some intellectual factors are about nonintellectual factors of innovation. In a word, the innovation knowledge ensures us to obtain, create and integrate all the necessary intellectual or nonintellectual factors of the innovation quality education.

The secondary aspect is that the innovation knowledge gives birth to bright ideas, which is the core making innovation innovative. In successful patents, one hundred percent belong here, for example. All new business that are described in the books on entrepreneurship are built around "bright ideas", such as the zipper, the ballpoint ten, the aerosol spray can, the tab to open soft drink or beer cans, etc. And what is more, research in many business aims at finding or exploiting bright ideas, whether for a new flavor in breakfast cereals or drinks, for a better running shoe, or for one more style of clothes. In the theory and practice of innovation and entrepreneurship, the bright-ideas means all, and are always appreciated and rewarded. It represents qualities that society needs initiation, ambition, and ingenuity. The importance of the innovation knowledge to bright ideas may stance from the cliché: One cannot promote what one does not understand. But when the innovation knowledge makes the bright ideas understandable, innovation is no more that difficult. Seen in this perspective, the resent trend in developed countries, and especially in the United States, to encourage individual student to come up with bright ideas, is long-sighted innovation education. In China, we can assist the innovation quality education by lowering patent fees, and by encouraging bright ideas as "competitive", for instance.

The above two aspects make a concrete pair of systematic contradictions, providing us with some kind of model to comprehend the innovation knowledge-centered structure for the system of innovation quality education. This systematic structure can be directive in establishing the evaluation system for innovation quality.

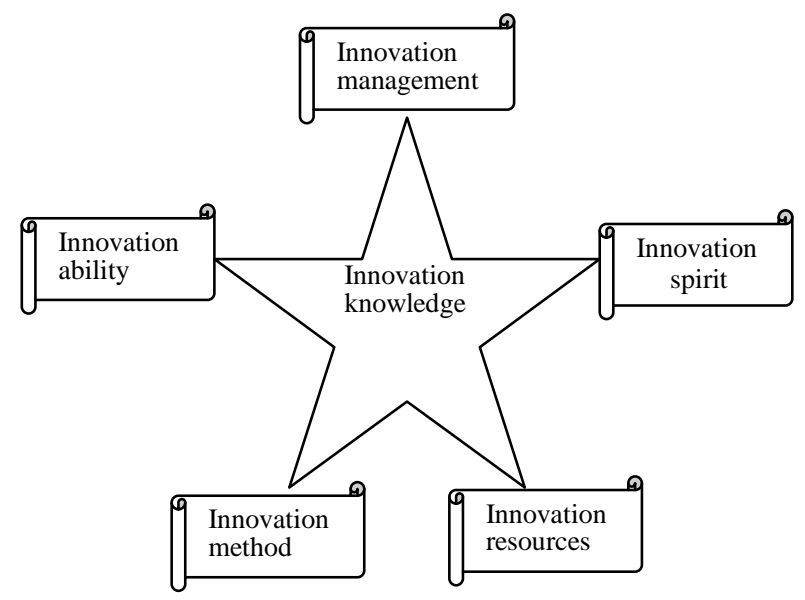

Fig. 2. Innovation knowledge centered education system 


\section{The InNOVATion KNOWLEDGe PROVIDES SystematiC CONSTRUCTION}

\section{A. The Innovation Knowledge Provides Methods for Innovation Quality Education}

The construction purpose of Marxist innovation education is set as to enhance the innovation quality of students. So in order to fulfill this qualitative purpose, requires the innovation knowledge to manifest its construction method, standards and its contents accordingly. As to the construction method, the above dialectical approach can be applied also in the innovation education field.

To be specific, the method is put here as systemconstructing method from two aspects clearly: the principle aspect is combination, and the secondary aspect is separation. That is the system-constructing method of separation and combination, which severs for the innovation method of any system-construction. The combination is based on the separation, probably always, obtains from the separation necessary conditions for the system-construction. The exceptions lie in the practice when system-deconstruction is a kind of innovation as well, though less often, by no means should be omitted. In the most cases of innovation, the separation in the system-deconstruction is carried out to prepare conditions for further combination. This is needless to say happens more often. Thus, by the construction method of separation and combination, fig. 2 is invented to display the standards and contents for the innovation quality oriented education.

It is for sure, that there are all kinds of construction methods to make a method system, such as the mass line approach of Marxism in practical innovation, and the method of systematic contradiction in theoretical innovation, but they can all be concluded as the method of separation and combination. Other concrete methods come out of its application, for example, the mass line approach is produced by applying the method into the innovation practice, where the separation and combination happen between the masses and its cadres. The masses separate from the state of aimless, and combine with leadership; the cadres separate from wishful thinking, and combine with reality, for instance.

\section{B. The Innovation Knowledge Provides Standards for Innovation Quality Education}

In terms of the construction standards, as it shows in the fig. 2 , all the standards or regulations should be systematic, be complimentary to each other, and make the innovation knowledge the center of system structure. By the materialist dialectics, the construction standards being a unity of opposites, the general standard is the principle aspect that requires the construction to be systematic, dominates all the specific standards. And the specific standard is the secondary aspect that is produced by the inter-combination with innovation knowledge of every field in innovation quality education, requires the education fields to be intellectualized, such as to be put in words, and to be programmed by software, so can then be complimentary to each other. Eventually, the interaction of general standard and specific standard forms a standard system. Though the specific standard functions the secondary aspect, only plays reactive role as to carry out the general standard of being systematic, it bears the potential lower system factors, the contents of the innovation quality education system. Because it is the specific standards that directly regulates the construction of education contents, and it is obvious that no innovation education system can be built without the specific standards making all the fields complimentary to each other to form a system.

When the specific standards are applied in the innovation quality education, we may have better chance direct innovation practice to succeed, and be capable in teaching students to distinguish which investments are likely to fail. And then by the combination of the general standard and the specific standards in all fields, we can provide the innovation quality education with a systematic evaluation; after all it must be quite embarrassing to have standards contradicting each other.

\section{The Innovation Knowledge Provides Contents for Innovation Quality Education}

In terms of the construction contents, as it shows in table 1, by the combination with other education field, we attain all the contents. The contents form a system of several layers, since the innovation knowledge itself should also be systematic. So, the knowledge of innovation quality is in the first layer, to discuss the concepts related to innovation quality, such as innovation, quality, and the inner contradiction of them, especially the innovation quality itself. Taking the concept "innovation" for example, the innovation knowledge should involve that the essence of innovation revealed by Marxism is "benefits driven creative practice that increased total benefits in deed"[3]. And the inner contradiction of innovation should be discussed as the contradiction of "benefits" and "creative practice”, not all creative practice makes innovation, only when combined with benefits. Take note here, each upper system factor is composed by the two aspects' interaction of lower system factors, and the two aspects makes a contradiction, with the former being principle functions decisive and the latter being secondary functions reactive. What's more, the latter can also be decisive in certain cases, such as when your systemconstructing comes to abortion halfway in lack of management software, here the innovation management functions decisive to the innovation knowledge, and then turns into the principle aspect.

Innovation spirit should be combined with the innovation knowledge in the same pattern. The inner contradiction of it can be analyzed as innovation awareness and innovation willpower, the former make students like and want to innovate, and the latter makes one dare and persist in innovating. The belief that you'll win, only if you keep on trying, is the effective result of the innovation willpower education. Though the innovations are based on motive power from the innovation spirit, it could only be obtained through innovation ability directly. With qualified innovation ability, the more often you try, the more often you are to succeed. Otherwise, the more often you try, the more often you are to lose.

The innovation ability is also an opposite unity of innovation methods and innovation resources. The table 1 lists 5 layers of innovation quality fields for the innovation 
knowledge to develop its contents, but it serves only for example. There are more construction layers to explore. However, in this contents construction practice, the effective innovation knowledge system can be established in details by applying the system-constructing method of the separation and combination. What has been testified are the fields of innovation spirit, of innovation method and of innovation resources, according to the previous research [4].

TABLE I. THE CONSTRUCTION CONTENTS BY INNOVATION KNOWLEDGE

\begin{tabular}{|l|c|c|c|c|l|}
\hline \multirow{2}{*}{$\begin{array}{l}\text { Innovation } \\
\text { Quality } \\
\begin{array}{l}\text { Construction } \\
\text { Contents }\end{array}\end{array}$} & $\begin{array}{c}\text { Innovation } \\
\text { spirit }\end{array}$ & $\begin{array}{c}\text { Innovation } \\
\text { ability }\end{array}$ & $\begin{array}{c}\text { Innovation } \\
\text { resources }\end{array}$ & $\begin{array}{c}\text { Innovation } \\
\text { method }\end{array}$ & $\begin{array}{l}\text { Innovation } \\
\text { management }\end{array}$ \\
\hline $\begin{array}{l}\text { innovation } \\
\text { knowledge }\end{array}$ & & & & & \\
\hline
\end{tabular}

\section{The InnOvation KnOWLEdGe Summary}

To sum up, the innovation knowledge is no only an important systematic factor in the innovation quality system, but also is the center of innovation quality education system. It is the innovation knowledge that makes innovation wanted, processed and completed. Otherwise, without the innovation knowledge, no innovative ideas can be brought forward, and nobody can find the "week" or "missing" link of the innovation process. And the innovation knowledge should combine with other layers of innovation quality, to form a system, if it is not systematic, we can't make a systematic definition of the problems that leading to success. The above 5 layers of innovation knowledge is prerequisite for the education of innovation quality, but far from enough. Attempts to improve the predictability of innovations have not been particularly successful. Equally unsuccessful have been attempts to identify the personal traits, behavior, or habits that make for a successful innovator. "Successful inventors," an old adage says, "keep on inventing. They play the odds. If they try often enough they will succeed.[5]" So, there are obviously still a lot of issues left for the innovation knowledge to function.
Researchers interested in relevant fields might need to verify the innovation knowledge system, and consider in what education environment the innovation knowledge can be applied efficiently. With these two aspects of work, the former provide constructing contents inwardly, the latter prepare conditions outwardly, and then we can systematically support Marxist innovation education, and can evaluate innovation education in details.

\section{ACKNOWLEDGMENT}

This research was financially supported by the scientific research fund project of Zhaoqing University, Grant NO.201738. Thanks to Zhaoqing University, for its financial assistance and for its beautiful research environments, and in terms of inspiration, thanks my mother, Mrs. DUAN Hejiao, who is also my beloved teacher.

\section{REFERENCES}

[1] Luo Qing, A Research on the Development of Marxist Theory of Innovation [D]. The PhD. degree paper of South China University of Technology,2012-05, pp.117.

[2] Luo Qing. Marxist Innovation Education Exemplified in the Automatic Culture of Cordyceps Militaris[A]. Proceedings of the 1st International Seminar on Education, Innovation and Economic Management (SEIEM 2016)[C].2016:4.

[3] Luo Qing, A Research on the Development of Marxist Theory of Innovation [D]. The PhD. degree paper of South China University of Technology,2012-05, pp. pp.137.

[4] http://kns.cnki.net/KCMS/detail/detail.aspx?dbcode=IPFD\&dbname=IP FDLAST2017\&filename=JNGP201612001026\&uid=WEEvREcwSIJHS ldTTEYzU3EyVWptVFFCZEVxT1Flc2lhTDdqd3BMOGNzRT0=\$9A4 hF_YAuvQ5obgVAqNKPCYcEjKensW4ggI8Fm4gTkoUKaID8j8gFw! !\&v=MDg2NTIOQ2hOS3VoZGhuajk4VG5qcXF4ZEVITU9VS3JpZlp1 RnZFU3ZsVUw3TUpGNFZMeVBNZnJHNEg5Zk5yWTIGWmVz

[5] Ni Xiao Jian, Business Studies in Theory and Practice--The Fundamentals of International Business Study, Microfilm and Copy Centre Ltd. New Zealand, 1999, pp.122. 